\title{
ONLAY MESH REPAIR OF INCISIONAL HERNIA IS EFFECTIVE WITH LOW RECURRENCE AND COMPLICATIONS
}

\author{
Gopinath H. Venkataraoㄹ, Arun Kumar Ragulapadu Vadde2, Suresh Birur Parameswarappa ${ }^{3}$
}

${ }^{1}$ Associate Professor, Department of General Surgery, Subbaiah Institute of Medical Sciences, Shimoga, Karnataka.

${ }^{2}$ Associate Professor, Department of General Surgery, Subbaiah Institute of Medical Sciences, Shimoga, Karnataka.

3 Professor and HOD, Department of General Surgery, Subbaiah Institute of Medical Sciences, Shimoga, Karnataka.

\section{ABSTRACT}

\section{BACKGROUND}

Incisional hernia after abdominal surgery is a well-known complication. Controversy still exists with respect to the choice of hernia repair technique.

Aims and Objectives- To study the complications and recurrence of onlay mesh repair for incisional hernia in rural population of South India.

\section{MATERIALS AND METHODS}

32 consecutive patients undergoing open incisional hernia repair with onlay mesh technique between May 2012 and Dec 2017 at a single institution were included in the study. Patients were followed up and examined by a consultant surgeon in the outpatient clinic, if there was a suspicion of an incisional hernia recurrence.

Design- A prospective observational study.

\section{RESULTS}

The study included 32 patients with 100\% follow-up. The median follow-up was 29.5 months (range 6 - 72). Recurrence of hernia was observed in 1 of 32 patients (3.13\%). Surgical site infections (SSI) are highest complications observed (9.38\%). The overall complication rate was $31.25 \%$.

\section{CONCLUSION}

This study with a long follow-up showed open incisional repair with onlay mesh has low recurrence. Surgical site infection (SSI) is the commonest complication observed.

\section{KEYWORDS}

Incision Hernia; Onlay Mesh Repair; Complication; Rural Population of South India.

HOW TO CITE THIS ARTICLE: Venkatarao GH, Vadde AKR, Parameswarappa SB. Onlay mesh repair of incisional hernia is effective with low recurrence and complications. J. Evolution Med. Dent. Sci. 2018;7(14):1737-1740, D0I: 10.14260/jemds/2018/392

\section{BACKGROUND}

Incisional hernias by definition develop at sites where an incision has been made for some prior abdominal procedure. Hernias are due to failure of fascial tissues to heal and close following laparotomy. Prosthetic mesh repair is associated with lower recurrence rate, but a higher incidence of complications. Complications commonly observed are wound infection, seroma collection, delayed wound healing, sinus formation, mesh migration, erosion of the mesh into the adjacent structures including the intestine, enterocutaneous fistula, intestinal obstruction and recurrence of ventral hernia. Recent data from the American Hernia Society Quality Collaborative (AHSQC) has shown comparable outcomes of onlay ventral hernia repair to other sublay techniques. Onlay ventral hernia repair was originally described by Chevrel in

'Financial or Other Competing Interest': None.

Submission 19-02-2018, Peer Review 16-03-2018,

Acceptance 22-03-2018, Published 02-04-2018.

Corresponding Author:

Dr. Arun Kumar Ragulapadu Vadde,

Associate Professor,

Department of General Surgery,

Subbaiah Institute of Medical Sciences,

Nidige Hobli, Holebenavalli Post,

Shimoga-577222, Karnataka, India.

E-mail:ak011956@gmail.com hvgnath@gmail.com

DOI: $10.14260 /$ jemds $/ 2018 / 392$

\section{(c) (i) $(\Theta$}

70 s. The focus of his original repair was recreation of the linea alba and the use of a premuscular prosthesis to buttress the primary closure. The most important feature is recreation of a tension-free midline.[1]

\section{MATERIALS AND METHODS}

This prospective observational study included 32 consecutive patients who underwent open incisional hernia repair with onlay technique between May 2012 to Dec 2017 at Subbaiah Institute of Medical Sciences and Teaching Hospital Purale, Shimoga, Karnataka, India, Department of General Surgery. The patients were diagnosed with physical examination and diagnostic imaging including ultrasonography (USG) and computed tomography (CT) for further evaluation. Informed consent was taken from all patients. The patient's age, sex location and size of the abdominal defect, the previous operation, operation findings, duration of hospitalisation, early and long-term complications and recurrences were recorded.

\section{Operation Technique}

All patients were operated under spinal or epidural anaesthesia. Cefotaxime 1 gram was given intravenously during anaesthesia induction. After cleaning of the skin with iodine solution, surgical incision was performed. The hernia sac was resected and contents reduced to the abdomen. Intact fascia, approximately $5 \mathrm{~cm}$ around the defect was dissected. All hernias disregarding size were operated by the same technique, which included closure of the hernia defect with 
non-absorbable sutures (Typically polypropylene no. 1). Polypropylene mesh was placed onto the anterior rectus fascia (onlay technique) with continuous and/ or interrupted $2 / 0$ and $3 / 0$ polypropylene sutures. Repair operations were carried out by senior surgeons at the institution. Two suction drains were placed above polypropylene mesh in all patients. Drains were taken when the daily drainage decreased below $20 \mathrm{cc}$.

\section{Follow-Up}

Patients were followed with outpatient clinic visits 1, 4 and 8 weeks after surgery and 6 monthly or yearly follow-up for 2 to 5 years. Patients with any complaints were subjected for clinical examination and ultrasonography (USG). The wound complications were defined. Any fluid and blood collection at incision site that needed surgical drainage accepted as seroma or haematoma respectively. Wound infection was determined with pus accumulation in subcutaneous region.

\section{Statistics for Statistical Analysis}

The statistical software package SPSS (Statistical Package for the Social Science) 16.0 for windows (SPSS Inc., Chicago, IL) was used. Frequencies of sex and complications were calculated. Descriptive statistics were performed for age and hospitalisation time.

\section{RESULTS}

A total of 32 patients had been operated with incisional hernia during our study period. There were 29 women and 3 men. The mean age was $55.12 \pm 9.749$ years (range $30-72$ ) Demographic characteristics of patients were shown in Table1. The hernia diagnosis was established with physical examination in all patients. The previous surgical intervention and the hernia occurrence in different incision types and number of previous attempts of repair had been documented in all patients and shown in Table 2. The most common incision that hernia had developed was lower midline incision (78\%). Two patients underwent emergency procedures following intestinal obstruction. All defects were repaired with onlay mesh technique. The size of mesh used varied in between $8 \times 6 \mathrm{~cm}$ to $20 \times 35 \mathrm{~cm}$. The mean duration of hospitalisation time was $4.53 \pm 1.819$ days (range 5 - 10). All patients were followed up $100 \%$. The median follow-up was 29.5 months (range 6 - 70 months). Table 3 lists the complications with statistical analysis. There was no recurrence in the group of previous incisional hernia surgery. One patient developed recurrence $(3.13 \%)$ after 30 months of follow-up, who did not belong to any of these patient group of complications. One patient had spontaneous mesh extrusion $(3.13 \%)$ through normal umbilicus rather from operated scar after 10 months (Fig). One patient (3.13\%) had enterocutaneous fistula, as she had received previous radiotherapy for gynaecological malignancy and she was operated as an emergency for intestinal obstruction. There were two (6.25\%) mesh infection and two (6.25\%) seroma formation after surgery. Three patients (9.38\%) had SSI of the wound. All these patients were managed with appropriate antibiotics and surgical drainage. The overall complication rate was $31.25 \%$ with a 'p' value- 0.00013 .

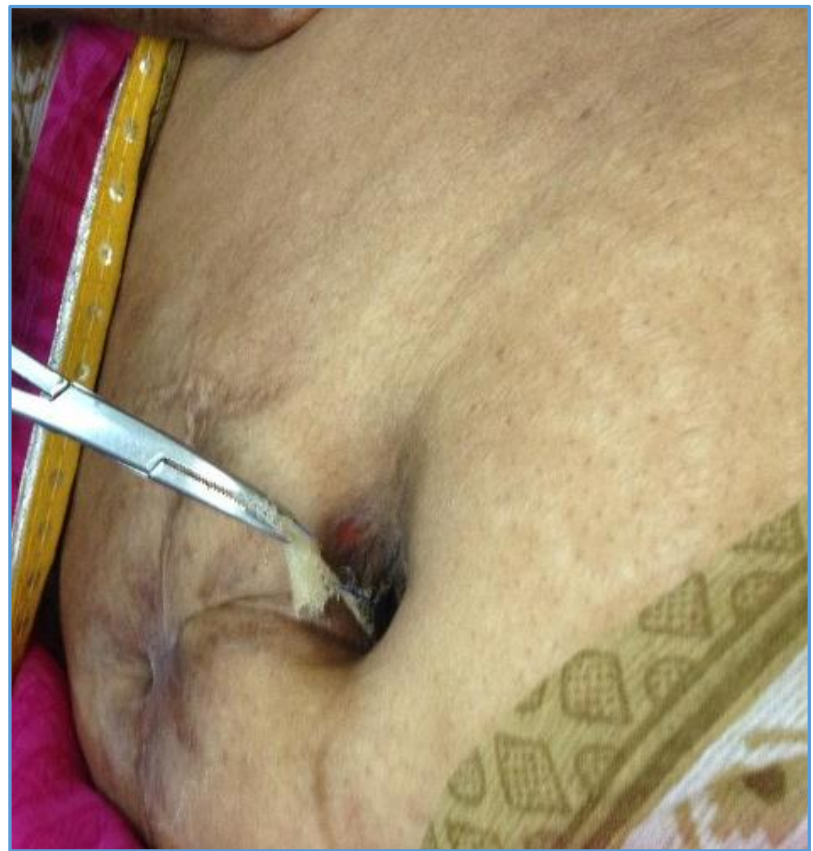

Figure 1. Spontaneous Extrusion of Mesh through Umbilicus. Note the Healthy Paramedian Scar of Hernia Surgery

\section{DISCUSSION}

In this study, we have shown a low long-term recurrence rate of $3.13 \%$ and an overall rate of complications of $31.27 \%$ after open hernia repair using the onlay mesh technique in our institution. SSI are highest complications observed (9.38\%). Incisional hernia repair is associated with a $15 \%$ complication rate.[2],[3] Andersen LPH et al has shown a low long-term recurrence rate of $15 \%$ and an overall rate of non-serious complications of $13 \%$ after open hernia repair using the onlay mesh technique in their institution. ${ }^{[4]}$ Juvany $M$ et al reports high recurrence rate on midline incisional hernia repair is still a concern (32\% at 5 years) and concludes to look for other strategies and more efficient surgical techniques for incisional hernia surgery, especially in obese patients. Our results are comparable to above reports and shows lesser recurrence and higher complications, most are non-serious.[5] Incisional hernia repair involves the use of a synthetic mesh and can be performed by conventional (open) surgery or minimallyinvasive (Laparoscopic) surgery. The surgical treatment of incisional hernia has changed rapidly during the last decade with the increasing use of mesh technique and the introduction of laparoscopy. However, many questions concerning mesh type, mesh positioning, fixation method and operation type still remain unanswered.[6],[7] However, recurrence rates after open repair tend to be lower compared to those after laparoscopic surgery.[8],[9] Patients with incisional hernia are a heterogeneous population with patient specific co-morbidity and innate differences (e.g. collagen formation quality).[9],[10] Mesh is a mandatory need to reach acceptable low recurrence rate, if the defect is larger than a trocar hernia. Ferrando et al have shown that meshes implanted on the abdominal aponeurotic layer showed better and early incorporation (higher collagen deposition, capillary density and cell accumulation) and increased tensile strength reflecting tighter anchorage to the abdominal wall.[11] It has also been experimentally demonstrated that polypropylene may shrink up to $30 \%$ after implantation,[12],[13] but the 
shrinkage has not been published in onlay position. These papers are not considered for tissue reaction which is caused by surgical preparation and the foreign body reaction resulted from the greater surface. Onlay technique requires little tissue dissection with an easy access to the hernia repair. These advantages should be taken into consideration when choosing between laparoscopy and open technique and when choosing between different open techniques.[10] The laparoscopic approach is generally associated with longer learning curve. It is also associated with high frequency of bowel perforations.[14] Sublay technique seems to be the most difficult among open abdominal wall reconstructions and it has longer learning curve, but shows acceptable outcome in expertise hands. Langer et al also confirmed that the most important prognostic factor following mesh repair is the surgeon's experience.[15] This makes the choice of technique most suitable for each patient even more difficult.[4],[16],[17] The onlay technique is a simple and effective repair operation with a short learning period for the surgeon. For open incisional hernia repair the choice between inlay, onlay and sublay technique is often based on tradition and the individual surgeon's expertise rather than scientific evidence. Onlay reconstruction is an equivalent option that provides acceptable low rate of recurrence.[4],[10] Dietz UA et al compared various surgical techniques and found no significant differences, neither for reoperation rate nor for complication and recurrence rates. The best surgical technique for a patient has to be decided on an individual basis.[18] In this study, we have noticed spontaneous mesh extrusion through umbilicus rather from scar, which we could not find in any literature we have searched. The most serious complication, though fortunately rare, is the development of enterocutaneous fistula. We had one enterocutaneous fistula in our series. The incidence of enterocutaneous fistula due to prosthetic mesh is higher in subfascial $(5.2 \%)$ than in onlay (2.6\%) position.[19],[20],[21] Obese patients with thinned out abdominal muscular wall may give difficult depth perception for a surgeon to do onlay mesh repair without causing injury to the underlying bowel loops.[22] The methods that are widely suggested to prevent the bowel injury during onlay mesh fixation are: (1). Placement of the omentum over the bowel loops before closing the laparotomy opening; (2). Peritoneum is always closed; (3). Under laparoscopic guidance with a 5-mm telescope, onlay open mesh fixation can be performed safely without injuring the wall of a bowel loop.[21],[22],[23]

\section{CONCLUSION}

Onlay mesh repair has shown promising results in our study and has acceptable recurrence rate, although patient's number is small. Surgical site infection is the most common complication. Rare complication of spontaneous mesh extrusion through umbilicus was also observed. The great challenge of incisional hernia surgery remains to reconcile the variability of the condition (e.g. risk factors and hernia characteristics) with the surgical options available (e.g. surgical techniques, surgical materials and expertise). The technique of mesh placement is still at surgeon's discretion and onlay mesh repair is a reliably safe both for low recurrence and managing mesh related complications on par with other similar studies.

\section{REFERENCES}

[1] Stoikes NF, Shahan CP, Webb D, et al. Onlay ventral hernia repair. In: Hope W, Cobb W, Adrales G, eds. Textbook of Hernia. Cham: Springer 2017.

[2] Kroese LF, Kleinrensink GJ, Lange JF, et al. External validation of the European hernia society classification for postoperative complications after incisional hernia repair: a cohort study of 2, 191 patients. J Am Coll Surg 2018;226(3):223-9.e1.

[3] Walgenbach M, Mathes T, Siegel R, et al. Mesh fixation techniques in primary ventral or incisional hernia repair. Cochrane Database of Systematic Reviews 2015.

[4] Andersen LP, Klein M, Gogenur I, et al. Long-term recurrence and complication rates after incisional hernia repair with the open onlay technique. BMC Surgery 2009;9:6. doi:10.1186/1471-2482-9-6.

[5] Juvany M, Hoyuela C, Carvajal F, et al. Long-term follow-up (at 5 years) of midline incisional hernia repairs using a primary closure and prosthetic onlay technique: recurrence and quality of life. Hernia 201822(2):319-24. Doi: 10.1007/s10029-018-1730-3.

[6] Eriksen JR, Gogenur I, Rosenberg J. Choice of mesh for laparoscopic ventral hernia repair. Hernia 2007;11(6):481-92.

[7] Korenkov M, Sauerland S, Arndt M, et al. Randomized clinical trial of suture repair, polypropylene mesh or autodermal hernioplasty for incisional hernia. $\mathrm{Br} \mathrm{J}$ Surg 2002;89(1):50-6.

[8] Itani KM, Hur K, Kim LT, et al. Comparison of laparoscopic and open repair with mesh for the treatment of ventral incisional hernia: a randomized trial. Arch Surg 2010;145(4):322-8.

[9] Klinge U, Conze J, Krones CJ, et al. Incisional hernia: open techniques. World J Surg 2005;29(8):1066-72.

[10] Baracs J, Sajjadi GS, Kelemen D, et al. Open treatment of abdominal wall hernias: mesh repair is superior to suture repair and onlay mesh is better than sublay mesh - five-year multicentric, prospective, randomised clinical trial. Surgery Curr Res 2016;6:270. doi:10.4172/2161-1076.1000270

[11] Ferrando JM, Vidal J, Armengol M, et al. Early imaging of integration response to polypropylene mesh in abdominal wall by environmental scanning electron microscopy: comparison of two placement techniques and correlation with tensiometric studies. World J Surg 2001;25(7):840-7. https://doi.org/10.1007/s00268001-0038-z ,

[12] Seiler CM, Deckert A, Diener MK, et al. Midline versus transverse incision in major abdominal surgery: a randomized, double-blind equivalence trial. (POVATI: ISRCTN60734227). Ann Surg 2009;249(6):913-20.

[13] O'Dwyer PJ, Courtney CA. Factors involved in abdominal wall closure and subsequent incisional hernia. Surgeon 2003;1(1):17-22.

[14] Müller-Riemenschneider F, Roll S, Friedrich M, et al. Medical effectiveness and safety of conventional compared to laparoscopic incisional hernia repair: a systematic review. Surg Endosc 2007;21(12):2127-36. 
[15] Langer C, Liersch T, Kley C, et al. Twenty-five years of experience in incisional hernia surgery. A comparative retrospective study of 432 incisional hernia repairs. Chirurg 2003;74(7):638-45.

[16] Temudom T, Siadati M, Sarr MG, et al. Repair of complex giant or recurrent ventral hernias by using tension-free intraparietal prosthetic mesh (Stoppa technique): lessons learned from our initial experience (fifty patients). Surgery 1996;120(4):738-43.

[17] McLanahan D, King LT, Weems C, et al. Retrorectus prosthetic mesh repair of midline abdominal hernia. Am J Surg 1997;173(5):445-9.

[18] Dietz UA, Menzel S, Lock J, et al. The treatment of incisional hernia. Dtsch Arztebl Int 2018;115(3):31-7. Doi: 10.3238/arztebl.2018.0031.

[19] Burger JW, Luijendijk RW, Hop WC, et al. Long-term follow-up of a randomized controlled trial of suture versus mesh repair of incisional hernia. Ann Surg 2004;240(4):578-85.
[20] Leber GE, Grab JL, Alexender AL, et al. Long-term complications associated with prosthetic repair of incisional hernias. Arch Surg 1998;133(4):378-82.

[21] Acar T, Gömceli I, Taçyildiz R, et al. Enterocutaneous fistula due to polypropylene mesh migration. Ir J Med Sci 2002;171(3):172, 174.

[22] Thirumalagiri VR, Satwalekar R, Polisetti R, et al. Late ileocutaneous fistula due to onlay mesh fixation after incisional hernia repair. J NTR Univ Health Sci 2014;3(2):107-10.

[23] Sistla SC, Reddy R, Dharanipragada $\mathrm{K}$, et al. Enterocutaneous fistula due to mesh fixation in the repair of lateral incisional hernia: a case report. Cases J 2008;1(1):370. 